\title{
Neuropsychiatry of frontal lobe dysfunction in violent and criminal behaviour: a critical review
}

\author{
M C Brower, B H Price
}

\begin{abstract}
Objectives-To establish the link between frontal lobe dysfunction and violent and criminal behaviour, based on a review of relevant literature.

Methods-Articles relating evidence of frontal lobe dysfunction with violence or crime were collected through a MEDLINE search using the keyword "frontal lobe" combined with the terms "aggression," "violence," "crime," "antisocial personality disorder," "psychopathy," "impulse control disorders", and "episodic dyscontrol." Reference lists were then searched for additional articles.

Results-High rates of neuropsychiatric abnormalities reported in persons with violent and criminal behaviour suggest an association between aggressive dyscontrol and brain injury, especially involving the frontal lobes. The studies reviewed support an association between frontal lobe dysfunction and increased aggressive and antisocial behaviour. Focal orbitofrontal injury is specifically associated with increased aggression. Deficits in frontal executive function may increase the likelihood of future aggression, but no study has reliably demonstrated a characteristic pattern of frontal network dysfunction predictive of violent crime.

Conclusions-Clinically significant focal frontal lobe dysfunction is associated with aggressive dyscontrol, but the increased risk of violence seems less than is widely presumed. Evidence is strongest for an association between focal prefrontal damage and an impulsive subtype of aggressive behaviour.
\end{abstract}

(F Neurol Neurosurg Psychiatry 2001;71:720-726)

Keywords: frontal lobe dysfunction; aggression; violence

Reports describing high rates of neuropsychiatric abnormalities among death row inmates, forensic psychiatric inpatients, and other persons with histories of violence have led to assertions that evidence of brain-behavioural impairment may mitigate or excuse criminal conduct. ${ }^{1-4}$ Frontal lobe dysfunction in particular, has been invoked to explain the actions of some persons charged with, or convicted of, violent crimes, who apparently fail to inhibit impulsive, trivially motivated, or habitual aggression..$^{5-7}$ But whereas clinical observation and current theories of prefrontal network function suggest that frontal lobe disorders may contribute to violent and criminal behaviour, the strength of this hypothesised association has yet to be established.

This paper evaluates the evidence for a causal relationship between abnormal frontal lobe function and violent crime, based on a review of current research literature. We located articles using a MEDLINE search from 1966 through 2000, combining the keyword "frontal lobe" with the terms "aggression," "violence," "crime," "antisocial personality disorder," "psychopathy," "impulse control disorders", and "episodic dyscontrol." We then conducted a hand search of relevant reference lists. Articles were selected for review if they contained clinical, laboratory, or neuropsychological test data relating frontal lobe function to aggression, crime, or violence. In this review, we adopt the definition of aggression as any threatening or physically assaultive behaviour directed at persons or the environment. "Violence" refers to actions that inflict physical harm in violation of social norms. We divide our findings under the following headings: (1) studies relating clinical focal frontal lobe disorders to violent behaviour; (2) studies reporting neuropsychological measures of frontal lobe function in aggressive and antisocial subjects; (3) studies of clinical neurological findings in violent and criminal populations; and (4) neuroimaging studies of aggressive and violent subjects. We conclude by assessing the magnitude and specificity of the hypothesised link between frontal lobe dysfunction and violence, and discuss implications for future research.

Focal frontal lobe disorders and violent behaviour

Case studies as far back as 1835 have reported the onset of antisocial personality traits after frontal lobe injury. ${ }^{8}$ Such cases typically involve damage to the orbitofrontal cortex, which clinical observation has associated with "poor impulse control, explosive aggressive outbursts, inappropriate verbal lewdness, jocularity, and lack of interpersonal sensitivity." Such gross dysregulation of affect and behaviour may occur while cognitive, motor, and sensory functioning remain relatively intact. ${ }^{10}$ Blumer 
and Benson dubbed this orbitofrontal syndrome "pseudopsychopathy," based on similarities to psychopathy-a personality type that, as defined by reliable and valid checklist criteria, is strongly associated with violence and criminality. ${ }^{11-13}$

Case reports have described a similar syndrome of "acquired sociopathy" in persons who had ventromedial prefrontal injury in adulthood. ${ }^{14-16}$ Although showing minimal impairments on standard neuropsychological tests of intelligence and executive functions, these subjects display marked deficits in real life tasks demanding judgment, awareness of socially appropriate conduct, and the capacity to assess future consequences. ${ }^{17}$ Persons with frontal network damage acquired before the age of 8 have also been reported to have adult histories of recurrent impulsive, aggressive, and antisocial behaviour, associated with primary deficits in tests of executive function, poor abstract conceptual thinking, inability to envision another person's subjective experience, and immature moral reasoning. ${ }^{18-20}$ One report, however, has described two cases of improvement in impulsive and antisocial behaviour after frontal traumatic brain injury in adulthood. $^{21}$

Large systematic studies on cohorts of war veterans with head injury have also tended to find an association between frontal lobe lesions and aggressive or antisocial behaviour, although the prevalence of actual violent crime seems small. Among German researchers who described personality changes in first world war and second world war veterans with frontal lobe injuries, Kleist found a consistent relation between orbitofrontal lesions and subsequent antisocial behaviour. ${ }^{8}$ Five patients (3\%) in a sample of 144 British second world war veterans with penetrating head injury committed "crimes and misdemeanors," though all five had damage limited to the frontal lobes. ${ }^{22}$ Less than $5 \%$ of all subjects with frontal lobe injury in a similar study of Finnish second world war veterans had a history of criminal conviction, and only one had committed a violent offence. ${ }^{23}$

The Vietnam Head Injury Study (VHIS) found that subjects with lesions limited to the frontal lobes tended to show more aggressive and violent behaviours compared with patients with non-frontal head injury and controls without head injury. ${ }^{24}$ About $14 \%$ of subjects with frontal lobe injury engaged in fights or damaged property, compared with about $4 \%$ of controls without head injury. The study also found a significant association between increased aggression and focal mediofrontal and orbitofrontal injury identified on brain CT. Reports have also found higher rates of antisocial behaviour (including stealing, physical assault, and sexual comments or advances) in patients with frontotemporal dementia, even when compared with equally cognitively impaired patients with Alzheimer's disease. ${ }^{25} 26$

All of these studies were retrospective, and most did not adequately control for known violence risk factors. The VHIS study, for example, did not report on prior history of aggression, substance misuse, stability of employment, socioeconomic status, the presence of psychiatric symptoms or disorders other than depression, or criminal charges or other legal involvement. Without such data, it remains unclear how much of the increases in aggressive behaviour found can be specifically attributed to focal frontal lobe injury.

Neuropsychological studies of aggressive and antisocial subjects

A previous comprehensive review of neuropsychological studies by Kandel and Freed (1989) found that "evidence for the association between specifically violent criminal behaviour and frontal lobe dysfunction is weak at best."27 A subsequent review by Pennington and Ozonoff concluded that comorbid attention deficit hyperactivity disorder (ADHD) most likely accounted for deficits in frontal executive function linked with adolescent conduct disorder, but considered that ADHD might worsen aggression in such cases. ${ }^{28}$ Table 1 summarises results of relevant neuropsychological studies reported since $1989 . .^{29-36}$

One study reported that errors on a single subtest in a battery of executive function measures correlated significantly with a diagnosis of antisocial personality disorder in a male community sample. ${ }^{29} \mathrm{~A}$ small study of subjects addicted to cocaine, all of whom met diagnostic criteria for antisocial personality disorder, found that high violence subjects as a group scored significantly better than low violence subjects on a widely accepted measure of frontal executive functioning. ${ }^{30}$ By contrast, two studies using a laboratory based procedure designed to elicit aggressive behaviour have correlated decreased performance on executive function tests with increased aggression in community samples of male subjects without neurological, psychiatric, or substance misuse histories. ${ }^{31} 32$

A prospective study found that low scores on executive function tests significantly predicted self reported aggression in 10 to 12 year old boys with paternal histories of substance misuse, but the results did not control for ADHD. ${ }^{33}$ The same lead authors conducted a subsequent case-control study of aggression in conduct disordered adolescent females, controlling for ADHD: low executive function scores retained a significant independent correlation with physically aggressive antisocial behaviour. ${ }^{34}$ In a 1 year prospective study of forensic psychiatric inpatients who had committed a violent crime, low scores on three tests of frontal executive function significantly predicted frequency of aggression, accounting for $57 \%$ of the variance. ${ }^{35}$ Although studies of psychopathic subjects have not demonstrated frontal executive dysfunction, ${ }^{27}$ one report found that, compared with non-psychopathic criminals, psychopathic criminals showed significant deficits on tests specifically selected to assess orbitofrontal and ventromedial functioning. $^{36}$

Overall, these neuropsychological studies tend to support a significant association between prefrontal executive dysfunction 
measured by neuropsychological testing and increased antisocial and aggressive behaviour. In populations with prior risk of antisocial behaviour or aggression, the presence of executive function deficits may have value in assessing the future likelihood of aggression. Studies of psychopathic subjects, however, suggest that standard tests of executive function may miss orbital or ventromedial prefrontal dysfunction relevant to aggression. Maturational delay in the development of the prefrontal cortex, ${ }^{37}$ or deficient education or socialisation related to psychosocial deprivation, or both ${ }^{29}{ }^{34}$ may also account for deficits found in neuropsychological test performance linked to aggression.

\section{Clinical neurological findings in violent and criminal populations}

A previous review concluded that antisocial subjects had more EEG abnormalities, predominantly anterior. ${ }^{39}$ Subsequent studies have continued to find abnormal frontal EEG activity, as well as diminished frontal event related potentials, correlating with antisocial personality disorder or histories of aggression. ${ }^{40-42}$ In a study of adult male drug misusers, for example, subjects rated as "high aggressive" on a self report scale showed statistically significant frontal EEG slowing relative to the "low aggressive" group. ${ }^{43}$ A case series describing recurrent, severe aggression in mentally retarded subjects attributed their behaviour to frontal lobe seizures, based on phenomenological similarities to frontal ictal automatisms; $60 \%$ of subjects had abnormal EEGs, with $20 \%$ having focal frontal or frontotemporal findings. ${ }^{44}$ Case reports have also linked orbitofrontal EEG spiking to violent hallucinations and assaultive behaviour. ${ }^{45}$ A study of 333 prisoners referred for evaluation after being charged with a violent crime specifically related frontal EEG findings to "habitual physical aggression or explosive rages." "46 After exclusion of subjects with clinical evidence of structural brain damage, $56.9 \%$ of habitually aggressive subjects had EEG abnormalities $(62.2 \%$ frontal), compared with $11.8 \%$ of other subjects who had committed a single, isolated aggressive act.

Another report of neurological findings in 31 subjects, who were referred by attorneys in connection with claims of mitigation related to murder charges, found that $64.5 \%$ showed "some physical evidence of frontal dysfunction." ${ }^{47}$ Signs elicited included snout, suck and grasp reflexes, paratonia, abnormal smooth pursuit eye movements, diminished word fluency, and reciprocal hand movement errors. Examination disclosed three or more signs in $32.3 \%$, two signs in $9.7 \%$, and one sign in $22.6 \%$. A retrospective chart review found that a frontal lobe lesion was the best predictor of involvement in a violent episode among inpatients on a neuropsychiatric unit, accounting for $11 \%$ of the variance, ahead of number of inpatient days, seizure disorder, history of alcohol misuse, and affective psychosis. ${ }^{48} \mathrm{~A}$ prospective study of frontal lobe function and violence in psychiatric inpatients with mood and psychotic disorders found no significant difference in frontal or other neurological findings between violent and non-violent patients. ${ }^{49}$ Persistently violent patients, however, had significantly more frontal lobe impairment than transiently violent patients and their behaviour seemed less responsive to environmental factors. A related study by the same

Table 1 Neuropsychological studies of frontal lobe function in aggressive and antisocial subjects

\begin{tabular}{|c|c|c|c|}
\hline Reference & Subjects & Neuropsychological test measure & Results \\
\hline$\overline{\text { Deckel et } a l^{29}}$ & $\begin{array}{l}89 \text { men, age } 21-25, \text { recruited from } \\
\text { community }\end{array}$ & $\begin{array}{l}\text { - WCST, COWT, PMT } \\
\text { - EEG }\end{array}$ & $\begin{array}{l}\text { - PMT VII Maze added significantly to } \\
\text { prediction of ASPD } \\
\text { - Decrease in left versus right frontal EEG } \\
\text { activation in ASPD }\end{array}$ \\
\hline Rosse $e t a l^{30}$ & $\begin{array}{l}14 \text { male crack cocaine addicted inpatients } \\
\text { with ASPD }\end{array}$ & WCST & $\begin{array}{l}\text { Low violence group made significantly } \\
\text { more perseverative errors than high violence } \\
\text { group }\end{array}$ \\
\hline $\begin{array}{l}\text { Giancola and } \\
\text { Zeichner }^{31}\end{array}$ & $\begin{array}{l}\text { Laboratory aggression in community } \\
\text { sample, } 72 \text { white men aged } 18-32\end{array}$ & SOP, CAT & $\begin{array}{l}\text { Increased aggression correlated with } \\
\text { decreased FL test performance }\end{array}$ \\
\hline Lau $e t a l^{32}$ & $\begin{array}{l}\text { Laboratory aggression and alcohol } \\
\text { intoxication in community sample, } 114 \\
\text { male social drinkers }\end{array}$ & SOP, CAT & $\begin{array}{l}\text { - Increased intoxication correlated with } \\
\text { increased aggression } \\
\text { - Lowest } 25 \% \text { on FL tests significantly more } \\
\text { aggressive }\end{array}$ \\
\hline Giancola et a ${ }^{33}$ & $\begin{array}{l}\text { Self reported aggression in } 198 \text { males aged } \\
10-12 \text { at risk for substance misuse, and } \\
\text { controls; } 2 \text { year prospective follow up }\end{array}$ & $\begin{array}{l}\text { PMT, vigilance task, forbidden toy task, } \\
\text { motor restraint task, WISC-R block design }\end{array}$ & $\begin{array}{l}\text { - Significantly lower EF scores in boys at risk } \\
\text { for substance abuse } \\
\text { - Low EF scores significantly predicted } \\
\text { increased aggression }\end{array}$ \\
\hline Giancola et a $\beta^{4}$ & $\begin{array}{l}\text { Case-control study of aggressive antisocial } \\
\text { behaviour in } 249 \text { conduct disordered } \\
\text { females, age } 14-18 \text {, and controls }\end{array}$ & $\begin{array}{l}\text { PMT, vigilance task, motor restraint task, } \\
\text { SCWT, WISC-R/WAIS-R block design, } \\
\text { picture arrangement and object assembly }\end{array}$ & $\begin{array}{l}\text { - CD subjects had significantly lower EF } \\
\text { scores } \\
\text { - Low EF scores significantly correlated with } \\
\text { aggression, even when controlling for ADHD }\end{array}$ \\
\hline Foster et $a l^{35}$ & $\begin{array}{l}\text { One year prospective study of aggression in } \\
23 \text { male forensic psychiatric inpatients }\end{array}$ & $\begin{array}{l}\bullet \text { SCWT, JLOT, SDMT, TONI, WCST, } \\
\text { EPT } \\
\text { • Overt aggression scale }\end{array}$ & $\begin{array}{l}\text { - Scores on SCWT, JLOT, and EPT only } \\
\text { significantly predicted frequency, but not } \\
\text { severity of aggression }\end{array}$ \\
\hline LaPierre $e t a l^{36}$ & $\begin{array}{l}30 \text { psychopathic male criminals compared } \\
\text { with } 30 \text { non-psychopathic male criminals }\end{array}$ & $\begin{array}{l}\text { - Visual go/no-go, PMT qualitative error } \\
\text { score, WCST, mental rotation task } \\
\text { - Modular smell identification test }\end{array}$ & $\begin{array}{l}\text { - Psychopathic subjects significantly } \\
\text { impaired on visual go/no-go, PMT errors and } \\
\text { olfactory identification } \\
\text { - WCST and mental rotation no different } \\
\text { from controls }\end{array}$ \\
\hline
\end{tabular}

WCST $=$ Wisconsin card sorting test; COWT=controlled oral word fluency test; PMT=Porteus maze test; WISC-R=Wechsler intelligence scale for children-revised; WAIS-R=Wechsler adult intelligence scale-revised; $\mathrm{FL}=$ frontal lobe; $\mathrm{EF}=$ executive functions; $\mathrm{SOP}=$ self ordered pointing task; $\mathrm{CAT}=\mathrm{conditional}$ associative learning task; SCWT=Stroop colour-word task; JLOT=judgment of line orientation test; SDMT=symbol digit modalities test; TONI=test of non-verbal intelligence; $\mathrm{EPT}=$ emotional perception test; $\mathrm{ASPD}=$ antisocial personality disorder; $\mathrm{CD}=$ conduct disorder. 
Table 2 Neuroimaging studies in violent and aggressive subjects

\begin{tabular}{|c|c|c|c|}
\hline Reference & Subjects & Methods & Results \\
\hline Raine $e t a l^{51}$ & $\begin{array}{l}21 \text { community volunteers with ASPD, } \\
\text { compared with } 26 \text { substance dependent } \\
\text { subjects, } 21 \text { psychiatric controls, and } 34 \\
\text { healthy controls }\end{array}$ & $\begin{array}{l}\text { Prefrontal volume as measured using MRI } \\
\text { brain scans }\end{array}$ & $\begin{array}{l}\text { - ASPD significant } 11.0 \% \text { reduction in } \\
\text { prefrontal gray matter compared with } \\
\text { controls; } 13.9 \% \text { reduction compared with } \\
\text { substance dependent group }\end{array}$ \\
\hline Woermann et a $\check{l}^{2}$ & $\begin{array}{l}24 \text { aggressive patients with TLE, compared } \\
\text { with } 24 \text { non-aggressive TLE patients and } 35 \\
\text { controls }\end{array}$ & $\begin{array}{l}\text { Voxel by voxel analysis of grey matter density } \\
\text { using MRI brain scans }\end{array}$ & $\begin{array}{l}\text { - Aggressive TLE patients had decreased left } \\
\text { frontal grey matter compared with } \\
\text { non-aggressive TLE and controls }\end{array}$ \\
\hline Kuruoglu $e t a p^{3}$ & $\begin{array}{l}40 \text { alcohol-dependent subjects ( } 15 \text { with } \\
\text { ASPD), compared with } 10 \text { age and sex } \\
\text { matched controls }\end{array}$ & Resting SPECT & $\begin{array}{l}\text { - ASPD subjects had significant anterior } \\
\text { frontal hypoperfusion compared with other } \\
\text { alcohol dependent subjects and controls }\end{array}$ \\
\hline Amen $e t a \tilde{l}^{4}$ & $\begin{array}{l}40 \text { aggressive psychiatric patients compared } \\
\text { with } 40 \text { non-aggressive psychiatric controls }\end{array}$ & Resting SPECT & $\begin{array}{l}\text { - Aggressive subjects showed decreased } \\
\text { activity in prefrontal cortex, increased activity } \\
\text { in left subcortical structures }\end{array}$ \\
\hline Hirono et $a l^{55}$ & $\begin{array}{l}10 \text { aggressive dementia patients compared } \\
\text { with } 10 \text { non-aggressive dementia patients }\end{array}$ & Resting SPECT & $\begin{array}{l}\text { - Aggressive subjects had significant left } \\
\text { anterior temporal and bilateral dorsofrontal } \\
\text { hypoperfusion } \\
\text { - No differences in orbitofrontal regions }\end{array}$ \\
\hline $\begin{array}{l}\text { Volkow and } \\
\text { Tancredi }^{56}\end{array}$ & $\begin{array}{l}\text { Four forensic psychiatric patients with } \\
\text { repetitive violence compared with four } \\
\text { normal controls }\end{array}$ & Resting PET $\left({ }^{15} \mathrm{O}\right.$-water and $\left.{ }^{18} \mathrm{FDG}\right)$ & $\begin{array}{l}\text { - Significantly decreased left temporal CBF } \\
\text { and metabolism in four patients } \\
\text { - Significant frontal decreases in two subjects } \\
\text { with "no remorse" }\end{array}$ \\
\hline Volkow et $a l^{7}$ & $\begin{array}{l}\text { Eight psychiatric patients with repetitive } \\
\text { violence compared with eight normal controls }\end{array}$ & Resting ${ }^{18}$ FDG PET & $\begin{array}{l}\text { - Seven of eight violent patients, one control } \\
\text { subject, showed multiple areas with } \\
\text { significantly decreased metabolism } \\
\text { - Violent patients showed significantly } \\
\text { greater reduction in bilateral prefrontal and } \\
\text { medial temporal regions }\end{array}$ \\
\hline \multirow[t]{2}{*}{ Goyer et $a \bar{l}^{8}$} & \multirow{2}{*}{$\begin{array}{l}17 \text { subjects with DSM-III personality } \\
\text { disorder (PD), } 43 \text { controls }\end{array}$} & - Activated ${ }^{18} \mathrm{FDG}$ PET & - Increased MAS correlated with decreased \\
\hline & & $\begin{array}{l}\text { - Self reported "impulsive aggression" on } \\
\text { modified aggression scale (MAS) } \\
\text { - CPT to assess prefrontal function }\end{array}$ & $\begin{array}{l}\text { orbitofrontal metabolism in PD subjects } \\
\text { - No differences in CPT performance }\end{array}$ \\
\hline Raine $e t a l^{59}$ & $\begin{array}{l}\text { Attorney referrals of } 41 \text { persons charged with } \\
\text { murder or manslaughter, matched controls }\end{array}$ & ${ }^{18} \mathrm{FDG}$ PET with frontal activation by $\mathrm{CPT}$ & $\begin{array}{l}\text { - "Murderers" showed significant bilateral } \\
\text { metabolic decreases in prefrontal cortex, and } \\
\text { left subcortical structures } \\
\text { - No differences in CPT performance }\end{array}$ \\
\hline Pietrini $e t a l^{62}$ & $\begin{array}{l}15 \text { young healthy volunteers selected for } \\
\text { visual imagery abilities }\end{array}$ & $\begin{array}{l}{ }^{15} \mathrm{O} \text {-water PET superimposed on averaged } \\
\text { brain MR scans }\end{array}$ & $\begin{array}{l}\text { Evoked aggressive imagery correlated with } \\
\text { significant decreases in ventromedial frontal } \\
\text { CBF }\end{array}$ \\
\hline
\end{tabular}

PET $=$ Positron emission tomography; SPECT $=$ single photon emission computed tomography; ${ }^{15} \mathrm{O}$ water $={ }^{15} \mathrm{Oxygen}$ water; ${ }^{18} \mathrm{FDG}={ }^{18} \mathrm{Flouorodeoxyglucose}$; $\mathrm{CBF}=$ cerebral blood flow; $\mathrm{CPT}=$ continuous performance task; $\mathrm{TLE}=$ temporal lobe epilepsy.

authors reported that frontal executive dysfunction was significantly associated with a history of community violence, but did not predict inpatient assaults. ${ }^{50}$

These studies indicate that clinical signs of frontal lobe dysfunction are prevalent in populations of persons prone to violent and antisocial behaviour. Most of the subjects, however, were either referred by attorneys, or had known or suspected neuropsychiatric disorders, and so do not represent violent criminals in general. The mere presence of EEG abnormalities or frontal neurological signs also does not explain whether, or how, such findings contributed to behaviour at the time of an alleged crime. Two parallel prospective studies do not support a retrospective report that frontal lobe findings predict violent behaviour in inpatient settings. Clinical evidence of frontal lobe dysfunction, however, does seem to be associated with recurrent or persistent aggression. ${ }^{4-50}$

\section{Neuroimaging in aggressive and violent subjects}

Morphometric and functional neuroimaging studies of aggressive and violent subjects have consistently found frontal lobe abnormalities (table 2). ${ }^{51-62}$ A well designed MRI brain volumetric study compared an antisocial personality disorder group with substance dependent, psychiatric and normal control groups. ${ }^{51}$ The subjects with an antisocial personality disorder showed significant differences on three measures: more violent crimes, more psychopathic traits; and reduced overall prefrontal grey matter volume. An MRI study of interictal aggression in temporal lobe epilepsy found that, compared with both normal controls and nonaggressive patients with temporal lobe epilepsy, patients with temporal lobe epilepsy with recurrent episodic aggression had statistically significant frontal grey matter reductions; the area of maximum difference involved the left anterior frontolateral cortex..$^{52}$

Three studies have used single photon emission computed tomography (SPECT) brain scanning to evaluate antisocial and aggressive behaviour. $^{53-55}$ A comparison of alcohol dependent subjects with healthy controls found that alcoholic subjects with an antisocial personality disorder had significantly greater frontal hypoperfusion than other alcoholic subjects. ${ }^{53}$ As a group, adolescent and adult psychiatric patients who had physically attacked another person or destroyed property showed significantly decreased prefrontal activity compared with matched, non-aggressive psychiatric patient controls. ${ }^{54}$ Compared with patients with non-aggressive dementia, patients with aggressive dementia with the same degree of cognitive and psychiatric impairments had significant left anterior temporal and bilateral superior frontal hypoperfusion, but no significant differences in orbitofrontal regions. ${ }^{55}$

Two positron emission tomography (PET) brain scan studies, which compared forensic psychiatric patients with normal controls, documented decreased frontal cortical blood flow or metabolism associated with "repetitive" 
and "purposeless" violent behaviour. ${ }^{56}{ }^{57} \mathrm{An}$ other PET study of "impulsive aggression" found that, compared with non-psychiatric controls, patients with personality disorders (chiefly antisocial, borderline, and narcissistic) showed decreased anterior medial and left anterior orbitofrontal metabolism, which correlated with increased scores on a self reported aggression scale. ${ }^{58}$ Frontal cortex metabolism did not distinguish patients with antisocial personality disorder from controls.

Another study examined 41 persons charged with murder or manslaughter, who were referred for PET in connection with psychiatric evaluations for criminal responsibility, competence to stand trial, or claims of mitigation. ${ }^{59}$ Compared with controls (matched for age, sex, and diagnosis of schizophrenia, if present), "murderers" as a group showed statistically significant bilateral prefrontal metabolic decreases during a frontal lobe activation task. A follow up report on the same subjects found that only those subjects blindly rated as lacking histories of psychosocial deprivation had significantly lower overall prefrontal metabolic rates. ${ }^{60}$ A further study separated these same subjects into "predatory" versus "affective" murderers, based on a forensic typology distinguishing controlled, purposeful aggression to achieve a desired goal from impulsive, emotionally charged aggression. ${ }^{61}$ Affective murderers had significantly lower prefrontal metabolic activity compared with controls, whereas frontal metabolism in predatory murderers resembled controls. In a PET study of healthy volunteer subjects who were instructed to imagine a scenario involving their own aggressive behaviour, visual evocation of unrestrained aggression correlated with significant focal reductions in ventromedial frontal blood flow, compared with an emotionally neutral scenario. $^{62}$

The cumulative evidence from these neuroimaging studies points to a strong association between increased aggression and reduced prefrontal cortical size or activity. Although most studies cite bilateral prefrontal abnormalities, others specifically cite left anterior frontal or orbitofrontal findings, as well as nonfrontal brain regions. These inconsistencies may reflect variation related to experimental conditions, limitations of imaging technology, or subject selection. Most of the subjects in these studies had known or suspected psychiatric disorders potentially contributing to alterations in prefrontal function. Studies using PET have documented focal decreases in frontal cortical activity associated with various neuropsychiatric disorders, as well as transient mental states, such as induced sadness, and episodes of mood disorder. ${ }^{63-65}$ The reported reductions in prefrontal size or activity may, therefore, represent a predisposition to affective states relevant to aggressive behaviour, without necessarily signifying an incapacity to avoid actual violent acts. ${ }^{66}$ The trend in neuroimaging findings, which associates prefrontal abnormalities with "purposeless" or affective aggression, as opposed to premeditated or predatory behaviour, supports this interpretation.

\section{Discussion}

The studies surveyed in this review indicate that clinically significant frontal lobe dysfunction is associated with aggressive dyscontrol. Subjects with both traumatic and neurodegenerative disorders primarily involving the prefrontal cortex display increased rates of aggressive and antisocial behaviour compared with subjects who have no, or non-frontal brain injury. Studies employing neuropsychological testing, neurological examination, EEG, and neuroimaging have also tended to find evidence for increased rates of prefrontal network dysfunction among aggressive and antisocial subjects. Prefrontal network dysfunction seems to be most specifically associated with a recurrent, impulsive subtype of aggression that may contribute to some violent behaviour. Two prospective studies suggest that in populations at risk for antisocial or aggressive behaviour, performance on neuropsychological tests of executive function may have value in assessing future likelihood of aggression. ${ }^{33}{ }^{35}$ No study, however, shows that disorders of prefrontal cortex predict violent crime.

Methodological problems in this literature include a lack of prospective data, small subject numbers and lack of adequate controls for known violence risk factors. Study samples often draw from groups (prisoners, attorney referrals, or those with severe neurological or psychiatric illness) that do not mirror the general population or even the larger criminal population. Reports describing persons charged with violent crimes tend to cite gross measures of brain function with low specificity and questionable clinical significance, while failing sufficiently to relate the clinical data to the specific aggressive behaviours in question. Standard neuropsychological tests of executive function typically employed in studies of antisocial subjects also may not detect orbitofrontal or ventromedial dysfunction relevant to aggressive behaviour. Although the bulk of research on violent and criminal behaviour points to multiple, probably interacting, causal factors, few studies attributing violent crime to frontal lobe dysfunction adequately address concurrent psychosocial variables such as emotional stress, drug and alcohol misuse, physical and sexual abuse, family breakdown, and poverty. ${ }^{4}$

Studies of subjects with acquired frontal lobe injury support the expected association of increased aggression with focal orbitofrontal, or ventromedial frontal injury, or both. The neuropsychological literature, however, tends to find increased aggressive behaviour associated with deficits in executive function, which correlate with dorsolateral prefrontal dysfunction. ${ }^{31}{ }^{32}$ One hypothesis to account for discrepant localisation data is that orbitofrontal and dorsolateral prefrontal dysfunction contribute to aggressive dyscontrol in different ways. Dorsolateral dysfunction may predominate in persons with comorbid features of fetal or birth 
related brain injury, developmental learning disorders, attention deficit hyperactivity disorder, substance misuse, and antisocial personality disorder. ${ }^{28}{ }^{67}$ Elliot characterised this group as having episodic aggressive dyscontrol rooted in "developmental deviance" manifested by "attention deficit disorder and minimal brain dysfunction," and associated with neurological soft signs and executive function deficits. ${ }^{68}$ Resulting educational and social failure likely contribute to aggressive and antisocial life adaptation, as well as to associated poor neuropsychological test performance. Executive function deficits, therefore, may increase the risk of violence via direct effects on impulse control or through associated psychosocial effects, or both, either interactively or independently.

Persons who have clinically evident neuropsychiatric disorders involving focal injury to structural-functional components of the frontal network, particularly the orbital and ventromedial prefrontal cortex, comprise a different group. Retrospective data strongly support a link between the disinhibited type of frontal network syndrome and aggressive dyscontrol. Case descriptions suggest that focal orbitofrontal injury specifically impairs capacities for social judgment, risk avoidance, and empathy that inhibit inappropriate or reflexive aggression. The actual frequency of violent behaviour, however, seems relatively low. Based on results reviewed here, ${ }^{24} 48$ a reasonable conjecture for the increased risk of violence associated with clinically significant focal frontal lobe injury might be $10 \%$ over the base rate for a given population. Confirmation of this estimate must await prospective studies.

In addition to using prospective design, future studies testing the relation between frontal lobe dysfunction and aggression should incorporate controls for known risk factors contributing to violent behaviour. Clinical description of the nature and extent of frontal lobe impairments, coupled with attention to the type (premeditated versus impulsive), frequency, and severity of aggressive behaviour, should help to clarify the brain-behaviour relations involved. Accurate measurement of the increased risk of violence in subjects with prefrontal dysfunction also requires comparison with rates of aggression in appropriate controls. The neuropsychiatric evaluation of violent patients should include clinical assessment for frontal lobe impairment and neuropsychological evaluation of executive functions, particularly in cases involving recurrent, impulsive aggression. Further progress in the study of aggression and frontal lobe dysfunction will require a forensically informed, interdisciplinary approach that integrates neuropsychiatric, neuropsychological, and psychophysiological methods for the study of brain localisation, social cognition, and emotional processing. Better understanding of brain injury and aggression can then inform medical, public health, and social policy interventions to prevent violence. ${ }^{69}$
We acknowledge Drs Shervert Frazier, Paul S Appelbaum, and Kenneth L Appelbaum, for their encouragement and support. We also thank Dr James Ellison for his helpful review of the manuscript.

1 Lewis DO, Pincus JH, Feldman M, et al. Psychiatric, neurological, and psychoeducational characteristics of 15 death row inmates in the United States. Am $\mathcal{f}$ Psychiatry 986;143:838-45.

2 Lewis DO, Pincus JH, Bard B, et al. Neuropsychiatric, psychoeducational, and family characteristics of 14 juveniles condemned to death in the United States. Am F Psychiatry 1988;145:584-9.

3 Martell DA. Estimating the prevalence of organic brain dysfunction in maximum-security forensic psychiatric patients. F Forensic Sci 1992;37:878-93.

4 Filley $\mathrm{CM}$, Price $\mathrm{BH}, \mathrm{Nell} \mathrm{V}$, et al. Toward an understanding of violence: neurobehavioral aspects of unwarranted physical aggression. Neuropsychiatry Neuropsychol Behav Neurol 2001;14:1-4.

5 Bear D, Freeman R, Greenberg M. Alterations in personality associated with neurologic illnesses. Psychiatry 1985;1: $1-13$.

6 Pincus JH. Aggression, criminality, and the frontal lobes. In: Miller BL, Cummings JL, eds, The human frontal lobes: funcMiller BL, Cummings JL, eds, The human frontal lobes: func-

7 Brower MC, Price BH. Epilepsy and violence: when is the Brower MC, Price BH. Epilepsy and violence: wher
brain to blame? Epilepsy Behavior 2000;1:145-9.

brain to blame? Epilepsy Behavior 2000;1:145-9.
8 Blumer D, Benson DF. Personality changes with frontal and temporal lobe lesions. In: Benson DF, Blumer D, eds. Psychiatric aspects of neurological disease. New York: Grune and Stratton, 1975.

9 Duffy JD, Campbell JJ III. The regional prefrontal syndromes: a theoretical and clinical overview. $f$ Neuropsychiatry Clin Neurosci 1994;6:379-87.

10 Mesulam, MM. Frontal cortex and behavior. Ann Neurol 1986;19:320-5.

11 Hare RD, Harpur TJ, Hakstian AR, et al. The revised psychopathy checklist: reliability and factor structure. Psychol Assess 1990;2:338-41.

12 Bodholdt RH, Richards HR, Gacono CB. Assessing psychopathy in adults: the psychopathy checklist-revised and screening version. In: Gacono CB, ed. The clinical and and screening version. In: Gacono CB, ed. The clinical and forensic assessment of psychopathy: a practicio

13 Hare RD, McPherson LM. Violent and aggressive behavior by criminal psychopaths. Special issue: empirical approaches to law and psychiatry. Int $\mathcal{F}$ Law Psychiatry 1984; 7:35-50.

14 Tranel D. Acquired sociopathy: the development of sociopathic behavior following focal brain damage. In: Fowles DC, P Sutker P, SH Goodman SH, eds. Progress in experimental personality and psychopathology research. Vol 17. New York: Springer, 1994

15 Meyers CA, Berman SA, Scheibel RS, et al. Case report: acquired antisocial personality disorder with unilateral left orbital frontal lobe damage. $\mathcal{F}$ Psychiatr Neurosci 1992;17: $121-5$.

16 Blair RJR, Cipolotti L. Impaired social response reversal: a case of acquired sociopathy. Brain 2000;123:1122-41.

17 Bechara A, Tranel D, Damasio H. Characterization of the decision-making deficit of patients with ventromedial decision-making deficit of patients with ventron
prefrontal cortex lesions. Brain 2000;123:2189-202.

18 Price BH, Daffner KR, Stowe RM, et al. The comportmental learning disabilities of early frontal lobe damage. Brain tal learning disabilities

19 Eslinger PJ, Grattan LM, Damasio H, et al. Developmental consequences of childhood frontal lobe damage. Arch Neurol 1992;49:764-9.

20 Anderson SW, Bechara A, Damasio H, et al. Impairment of social and moral behavior related to early damage in human prefrontal cortex. Nat Neurosci 1999;2:1032-7.

21 Labbatte LA, Warden D, Murray GB. Salutary change after frontal brain trauma. Ann Clin Psychiatry 1997;9:27-30.

22 Lishman WA. Brain damage in relation to psychiatric disability after head injury. Br F Psychiatry 1968;114:373410.

23 Virkkunen M, Nuutila A, Huusko S. Effect of brain injury on social adaptability. Acta Psychiatr Scand 1976;53:16872 .

24 Grafman J, Schwab K, Warden D, et al. Frontal lobe injuries, violence and aggression: a report of the Vietnam injuries, violence and aggression: a report of

25 Stip E. Compulsive disorder and acquired antisocial behavior in frontal lobe dementia. F Neuropsychiatry Clin Neurosci ior in frontal

26 Miller BL, Darby A, Benson DF, et al. Aggressive, socially disruptive and antisocial behavior associated with frontotemporal dementia. Br f Psychiatry 1997;170:150-5.

27 Kandel E, Freed D. Frontal-lobe dysfunction and antisocial behavior: a review. f Clin Psychol 1989;45:404-413.

28 Pennington BF, Ozonoff S. Executive functions and developmental psychopathology. I Child Psychol Psychiatry 1996;37:51-87.

29 Deckel AW, Hesselbrock V, Bauer L. Antisocial personality disorder, childhood delinquency, and frontal brain functioning: EEG and neuropsychological findings. $f$ Clin Psychol 1996;52:639-50.

30 Rosse RB, Miller MW, Deutsch SI. Violent antisocial Rosse RB, Miller MW, Deutsch SI. Violent antisocial
behavior and Wisconsin card sorting test performance in cohavior and Wisconsin card sorting test performance addicts [letter]. Am f Psychol 1993;150:170.

31 Giancola PR, Zeichner A. Neuropsychological performance on tests of frontal-lobe functioning and aggressive behavior in men. $\mathcal{F}$ Abnorm Psychol 1994;103:832-5. 
32 Lau MA, Pihl RO, Peterson JB. Provocation, acute alcohol intoxication, cognitive performance, and aggression. $\mathcal{F}$

33 Giancola PR, Moss HB, Martin CS, et al. Executive cognitive functioning predicts reactive aggression in boys at high risk for substance abuse: a prospective study. Alcohol Clin Exp Res 1996;20:740-4

34 Giancola PR, Mezzich AC, Tarter RE. Executive cognitive functioning, temperament, and antisocial behavior in conduct-disordered adolescent females. F Abnorm Psychol 1998;107:629-41.

35 Foster HG, Hillbrand M, Silverstein M. Neuropsychological deficit and aggressive behavior: a prospective study. Prog Neuropsychopharmacol Biol Psychiatry 1993;17:939-46.

36 LaPierre D, Braun CMJ, Hodgins S. Ventral frontal deficits in psychopathy: neuropsychological test findings. Neuropsychologia 1995;131:139-51.

37 Pontius AA, Ruttiger KF. Frontal lobe system maturational lag in juvenile delinquents shown in the narratives test. Adolescence 1976;11:509-18.

38 Lueger RJ, Gill KJ. Frontal-lobe cognitive dysfunction in conduct disorder adolescents. F Clin Psychol 1990;46:696706 .

39 Mednik SA, Volavka J, Gabrielli WF, et al. EEG as a predictor of antisocial behavior. Criminology 1982;19:219-31

40 Bauer LO, O'Connor S, Hesselbrock VM. Frontal P300 decrements in antisocial personality disorder. Alcohol: Clin Exp Res 1994;18:1300-5.

41 O'Connor S, Bauer L, Tasman A, et al. Reduced P3 amplitudes are associated with both a family history of alcoholism and antisocial personality disorder. $\operatorname{Prog~Neu}-$ ropsychopharmacol Biol Psychiatry 1994;18:1307-21.

42 Finn PR, Ramsey SE, Earleywine M. Frontal EEG response to threat, aggressive traits and a family history of alcoholism: a preliminary study. F Stud Alcohol 2000;61:3845.

43 Fishbein DH, Herning RI, Pickworth WB, et al. EEG and brainstem auditory evoked response potentials in adult male drug abusers with self-reported histories of aggressive male drug abusers with self-reported histories
behavior. Biol Psychiatry 1989;26:595-611.

44 Gedye A. Episodic rage and aggression attributed to frontal lobe seizures. Fournal of Mental Deficiency Research 1989:33:369-79.

45 Fornazzari L, Farcnik K, Smith I, et al. Violent visual hallucinations and aggression in frontal lobe dysfunction clinical manifestations of deep orbitofrontal foci. $\mathcal{F}$ Neuropsychiatry Clin Neursci 1992;4:42-4.

46 Williams D. Neural factors related to habitual aggression: consideration of differences between those habitual aggressives and others who have committed crimes of violence. Brain 1969;92:503-20.

47 Blake PY, Pincus JH, Buckner C. Neurologic abnormalities in murderers. Neurology 1995;45:1641-7.

48 Heinrichs RW. Frontal cerebral lesions and violent incidents in chronic neuropsychiatric patients. Biol Psychiatry 1989; 25:174-8.

49 Krakowski M, Czobor P. Violence in psychiatric patients: the role of psychosis, frontal lobe impairment, and ward the role of psychosis, frontal lobe impair
turmoil. Compr Psychiatry 1997;38:230-6.

50 Krakowski M, Czobor P, Carpenter MD, et al. Community violence and inpatient assaults: neurobiological deficits. $\mathcal{F}$ Neuropsychiatry Clin Neurosci 1997;9:549-55.
51 Raine A, Lencz T, Bihrle S, et al. Reduced prefrontal gray matter volume and reduced autonomic activity in antisocial

52 Woerman FG, van Elst LT, Koepp MJ, et al. Reduction of frontal neocortical grey matter associated with affective aggression in patients with temporal lobe epilepsy: an objective voxel by voxel analysis of automatically segmented MRI. F Neurol Neurosurg Psychiatry 2000;68:1629.

53 Kuroglu AC, Arikan Z, Vural G, et al. Single photon emission computerized tomography in chronic alcoholism. Br F Psychiatry 1996;169:348-54.

54 Amen DG, Stubblefield M, Carmichael B, et al. Brain SPECT findings and aggressiveness. Ann Clin Psychiatry 1996:8;129-37.

55 Hirono N, Mega M, Dinov I, et al. Left frontotemporal hypoperfusion is associated with aggression in patients with dementia. Arch Neurol 2000;57:861-6.

56 Volkow ND, Tancredi L. Neural substrates of violent behavior: a preliminary study with positron emission tomography. $B \mathcal{f}$ Psychiatry 1987;151:668-73.

57 Volkow ND, Tancredi LR, Grant C, et al. Brain glucose metabolism in violent psychiatric patients: a preliminary study. Psychiatry Res 1995;61:243-53.

58 Goyer PF, Andreason PJ, Semple WE, et al. Positronemission tomography and personality disorders. Neuropsychopharmacology 1994;10:21-8.

59 Raine A, Buchsbaum M, LaCasse L. Brain abnormalities in murderers indicated by positron emission tomography. Biol Psychiatry 1997;42:495-508.

60 Raine A, Stoddard J, Bihrle S, et al. Prefrontal glucose deficits in murderers lacking psychosocial deprivation. Neuropsychiatry Neuropsychol Behav Neurol 1998;11:1-7.

61 Raine A, Meloy JR, Bihrle S, et al. Reduced prefrontal and increased subcortical brain functioning assessed using positron emission tomography in predatory and affective murderers. Behav Sci Law 1998;16:319-32.

62 Pietrini P, Guazzelli M, Basso G, et al. Neural correlates of imaginal aggressive behavior assessed by positron emission tomography in healthy subjects. Am f Psychiatry 2000;157: 1772-81

63 Volkow ND, Fowler JS. Neuropsychiatric disorders: investigation of schizophrenia and substance abuse. Semin Nucl Med 1992;22:254-67.

64 Mayberg H. Limbic-cortical dysregulation: a proposed model of depression. In: Salloway S, Malloy P, Cummings $\mathrm{JL}$, eds The neuropsychiatry of limbic and subcortical disorders. Washington, DC: American Psychiatric Press, 1997.

65 Blumberg HP, Stern E, Ricketts S, et al. Rostral and orbital prefrontal cortex dysfunction in the manic state of bipolar disorder. Am $\mathcal{F}$ Psychiatry 1999;156:1986-8.

66 Mayberg H. Medical-legal inferences from functional neuroimaging evidence. Semin Clin Neuropsychiatry 1996; 1:195-201.

67 Kandel E. Biology, violence and antisocial personality. $f$ Forensic Sci 1992;37:912-18.

68 Elliot FA. Neurology of aggression and episodic dyscontrol. Semin Neurol 1990;10:303-12.

69 Filley CM, Kelly JP, Price BH. Violence and the brain: an urgent need for research. Scientist 2001;15:39. 